\title{
Tailored suprainsular partial hemispherotomy: a new functional disconnection technique for stroke-induced refractory epilepsy
}

\author{
Didier Scavarda, MD, ${ }^{1}$ Tiago Cavalcante, MD, ${ }^{1}$ Agnès Trébuchon, MD, PhD, ${ }^{2,3}$ Anne Lépine, MD, ${ }^{4,5}$ \\ Nathalie Villeneuve, MD, ${ }^{4,5}$ Nadine Girard, MD, ${ }^{6}$ Aileen McGonigal, MD, PhD, ${ }^{2,3}$ \\ Mathieu Milh, MD, $\mathrm{PhD},{ }^{4}$ and Fabrice Bartolomei, $\mathrm{PhD}^{2,3}$
}

Services de ${ }^{1}$ Neurochirurgie Pédiatrique, ${ }^{3}$ Neurophysiologie Clinique, ${ }^{4}$ Neurologie Pédiatrique, and ${ }^{6}$ Neuroradiologie, AP-HM, Hôpital de la Timone; ${ }^{2}$ nnstitut de Neurosciences des Systèmes, Aix Marseille Université; and ${ }^{5}$ Hôpital Henri Gastaut, Marseille, France

\begin{abstract}
OBJECTIVE Hemispherotomy is currently the most frequently performed surgical option for refractory epilepsy associated with large perinatal or childhood ischemic events. Such an approach may lead to good seizure control, but it has inherent functional consequences linked to the disconnection of functional cortices. The authors report on 6 consecutive patients who presented with severe epilepsy associated with hemiplegia due to stroke and who benefitted from a new, stereoelectroencephalography-guided partial disconnection technique.
\end{abstract}

\begin{abstract}
METHODS The authors developed a new disconnection technique termed "tailored suprainsular partial hemispherotomy" (TSIPH). Disconnection always included premotor and motor cortex with variable anterior and posterior extent.

RESULTS At a mean follow-up of 28 months, there were no deaths and no patient had hydrocephalus. Motor degradation was observed in all patients in the 2 weeks after surgery, but all patients completely recovered. The 6 patients were seizure free (Engel class IA) at the last follow-up. No neuropsychological aggravation was observed.
\end{abstract}

CONCLUSIONS TSIPH appears to be a conservative alternative to classic hemispherotomy, leading to favorable outcome in this series.

https://thejns.org/doi/abs/10.3171/2018.5.PEDS17709

KEYWORDS focal epilepsy; disconnection surgery; SEEG; insula; stroke; children

$\mathrm{S}$ TROKE in children is a rarely reported disease, but it is increasingly being recognized as a major cause of morbidity. ${ }^{26,27,37}$ Postnatal strokes occur predominantly with 2 peaks of frequency: in the 1st year of life and at the end of the 1st decade. Its incidence varies from 1.2 to 13.0 per $100,000^{25,37}$ with a male predominance. ${ }^{37}$ In addition, perinatal arterial ischemic stroke, defined as focal disruption of cerebral blood flow occurring between 20 weeks of gestation and postnatal day 28 , is the second most common etiology of neonatal seizures, following perinatal asphyxia. In most cases of perinatal stroke, no specific etiology is found. ${ }^{19}$ Together with developmental anomalies and motor deficits, seizures are a major symptom of perinatal cerebral infarcts. ${ }^{29}$
The incidence of seizures after stroke occurring in children has been poorly investigated. ${ }^{4-6,14,24,35}$ In a study by Singh et al., $25 \%$ of children with stroke presented with seizures during the acute period. ${ }^{35}$ None of the children without acute seizures developed seizure in the follow-up period, while $25 \%$ of the children with acute seizures went on to develop epilepsy. ${ }^{35}$ Refractory epilepsy after stroke is the major predicting factor of a poor functional outcome, especially during brain development. ${ }^{15,20,27,34}$ The incidence of refractory stroke-induced epilepsy in children has been estimated at around $5 \% .5,38$

In terms of surgery for refractory epilepsy associated with large ischemic lesions, some options, such as cyst fenestration, perilesional corticectomy, multilobar resec-

ABBREVIATIONS EZ = epileptogenic zone; MCA = middle cerebral artery; $m R S$ = modified Rankin Scale; SEEG = stereoelectroencephalography; TSIPH = tailored suprainsular partial hemispherotomy.

SUBMITTED December 13, 2017. ACCEPTED May 22, 2018.

INCLUDE WHEN CITING Published online August 24, 2018; DOI: 10.3171/2018.5.PEDS17709. 
tions/disconnections, and hemispheric disconnections, have been described. ${ }^{22}$ Given the extent of the ischemic damage in the affected hemisphere, hemispherectomy has been proposed in such cases and was the first surgical option leading to impressive results in terms of seizure control. ${ }^{33,34}$ An evolution of this radical surgical option was subsequently described, termed "functional hemispherotomy," which decreased the risk of superficial siderosis, hydrocephalus, and shunt requirement. ${ }^{7}$ However, the term "functional" in this procedure is more related to the sparing of cortical tissue than sparing of function per se. Indeed, hemispherotomy is very effective for seizure control but does not improve the cognitive prognosis. ${ }^{34}$ More conservative disconnection procedures have been proposed in cases of large lesions involving the posterior quadrant of the hemisphere, such as temporo-parietal-occipital disconnection. ${ }^{11,30}$

Here, we describe a new partial disconnection technique that includes the perimotor cortex (suprainsular disconnection) and is guided by stereoelectroencephalography (SEEG) results in 6 patients who presented with stroke in early life and severe drug-resistant epilepsy. We have termed this technique "tailored suprainsular partial hemispherotomy" (TSIPH). These patients were selected from a cohort of more than 400 patients who underwent exploration with SEEG procedures in the last 18 years. In particular, all patients with infantile stroke and drug-resistant epilepsy have been investigated using SEEG in the last 7 years at our center. Based on SEEG results, this procedure has the advantage of avoiding a large, complete disconnection of regions spared by the epileptogenic process.

\section{Methods}

\section{Patients and Presurgical Evaluation}

The patients were retrospectively selected from our epilepsy surgery database (starting in 2001, 411 SEEG cases). We included all patients presenting with stroke-induced drug-resistant focal epilepsy who underwent exploration with SEEG for presurgical epilepsy evaluation and subsequently underwent TSIPH to disconnect the epileptogenic zone (EZ). We included patients with stroke of probable perinatal origin or stroke that occurred during childhood.

Noninvasive presurgical workup was performed at the Henri Gastaut Hospital or La Timone Hospital in Marseille, or in the Toulouse CHU for 1 patient. All patients underwent detailed clinical examination, surface videoelectroencephalography recording of seizures, cerebral MRI, functional imaging, and neuropsychological assessment.

The decision to perform SEEG was made according to the French guidelines criteria ${ }^{21}$ to precisely define the EZ. In particular, despite the extent of brain damage in the present cases, a focal onset could be suspected from the noninvasive evaluation. Invasive measurements consisted of SEEG recordings obtained over a number of days. It was performed following discussion by a multidisciplinary team, utilizing the clinical and imaging data and results from the noninvasive investigations. The number and position of the implanted electrodes were also discussed.

Implantation of the intracerebral electrodes was per- formed in the Marseille Timone Hospital neurosurgical department for 5 patients and in the Toulouse neurosurgical department for 1 patient. The 4 children/adolescents underwent frameless SEEG ${ }^{10}$ and the 2 adult patients had frame-based SEEG. ${ }^{2}$ The pattern of implantation was designed to be able to identify the EZ and, if surgery was deemed possible, to delineate the anterior and posterior resection margins as well as an inferior limit up to the medial cerebral fissure (Fig. 1). Adequate localization of the electrodes in the cerebral space was verified using 1.5-T MRI or fusion of the preimplantation MR image and CT scan with the electrodes in place. SEEG recordings were performed using intracerebral multiple contact electrodes (10-15 contacts: $2 \mathrm{~mm}$ in diameter, Dixie Medical). The anatomical targeting and number of necessary electrodes were established in each patient according to the hypotheses for localization of the EZ determined by the clinical data and EEG recordings from phase 1 (i.e., the noninvasive preoperative workup). Particularly with the objective of avoiding complete hemispheric disconnection, the planning of electrode placement was established to explore the cortical areas around the ischemic areas and to explore the anteroposterior and craniocaudal limits of the EZ. Each electrode contained multiple contact points numbered 1 to 15. The SEEG recordings were prolonged as long as necessary to capture several of the patient's habitual seizures.

In addition, patients were evaluated for cerebrovascular abnormalities, cardiac disease, and the presence of any hematological or metabolic risk factors for stroke based

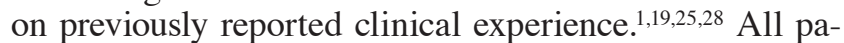
tients underwent a comprehensive battery of standardized neuropsychological tests, exploring intelligence and memory (immediate and delayed verbal and visual memory). Patients underwent neuropsychological evaluation when possible. The standard clinical measures of intelligence retained for IQ evaluation were the Wechsler Intelligence Scale for Children-Fourth Edition for patients 6 to 16 years and the Wechsler Adult Intelligence Scale-Third Edition for patients older than 16 years. Memory abilities with verbal and/or visual material and attention/working memory were assessed using the Wechsler Memory Scale-III for patients older than 16 years and the Children's Memory Scale for patients 6 to 16 years. We used the modified Rankin Scale (mRS) to assess the degree of disability (score 0, no symptoms; score 1, able to carry out all usual activities despite symptoms, normal development; score 2, unable to carry out all activities but has ageappropriate independence and no reduction in gross motor skills; score 3, requiring some help but able to walk without assistance, reduction of 1 level in gross motor skills in younger children; score 4, unable to walk without assistance but able to attend to own bodily needs, or reduction of at least 2 levels in motor skill development; and score 5 , bedridden, incontinent, and requiring constant care). ${ }^{3,16}$ Postoperative seizure outcome was assessed using Engel classification. ${ }^{13}$ Clinical data were collected 1 month after surgery and every 6 months in outpatient clinics during the follow-up period.

\section{Operative Technique}

The patient was positioned supine on the operating 

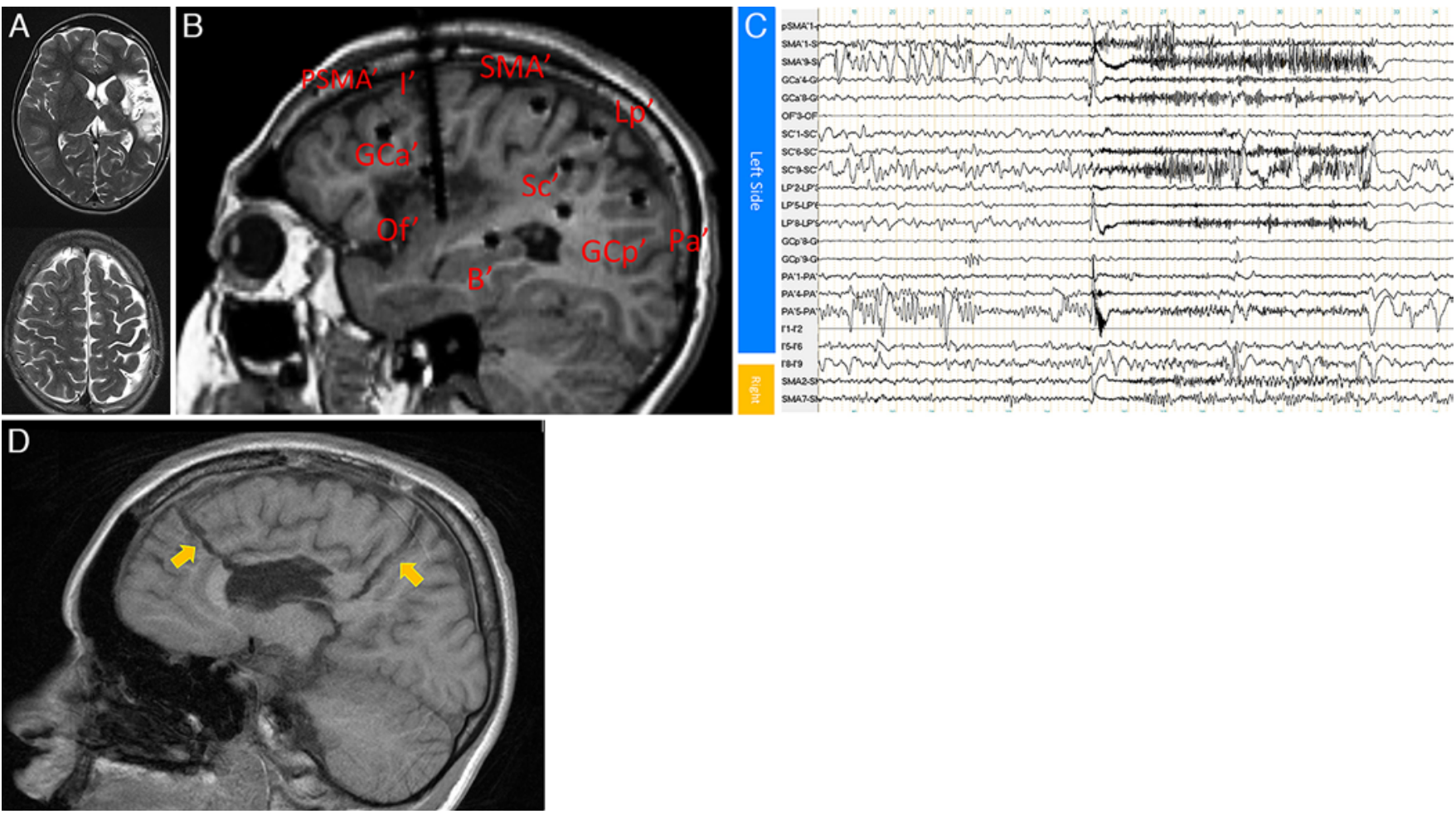

FIG. 1. Example of SEEG exploration. A: Axial MR images showing the stroke sequelae in the right MCA territory. B: Sagittal MR image showing SEEG implantation of the electrodes. C: SEEG traces of a typical seizure. The rapid discharge appears distributed over different regions but was prominent on the left side and in the premotor cortex (SMA' electrode) and the central cortex (Sc' electrode). D: MRI (sagittal plane) showing the disconnection (arrows). Electrodes implanted in the left side at the following locations: $\mathrm{B}^{\prime}=$ body of the left hippocampus; $\mathrm{GCa}$ ' = left anterior cingulum; $\mathrm{GCp} \mathrm{p}^{\prime}=$ left posterior cingulum; I' = left oblique insular electrode; $L p^{\prime}=$ left paracentralis lobule; Of' = left frontal operculum; $\mathrm{Pa}^{\prime}=$ left parietal area; $P S M A^{\prime}=$ left premotor area; $\mathrm{Sc}^{\prime}=$ left central sulcus; $\mathrm{SMA}^{\prime}=$ left supplementary motor area. Figure is available in color online only.

table. The head was turned to the contralateral side with a gel pad under the ipsilateral shoulder to avoid extreme rotation of the neck. Using neuronavigation, we delineated the anterior and inferior points of the 2 cortical incisions on the skin. The skin incision is a standard question-mark incision exceeding the midline and including the 2 incision lines. The craniotomy was delineated similar to the one performed for periinsular hemispherotomy and extended from below the sylvian fissure to the midline. It is not necessary to reach the midline and can be stopped 1 $\mathrm{cm}$ away from it (Fig. 2).

Suprainsular disconnections were performed in a tailored fashion (Fig. 3) under neuronavigation guidance (StealthStation S7, Medtronic) and using microscopic amplification. The first step was to delineate the 4 extremity points of the anterior and posterior vertical disconnection lines (points $\mathrm{A}$ and $\mathrm{B}$ for the anterior disconnection line; points $\mathrm{C}$ and $\mathrm{D}$ for the posterior line) based on the SEEG results. The second step was a suprainsular approach to the lateral ventricle between points $\mathrm{A}$ and $\mathrm{C}$. This approach can be performed in a subpial fashion; as the medial border of the insular cortex is reached, the trajectory must ascend to reach the ventricle if it is not dilated (not to enter the thalamus). The third step consisted of anterior and posterior disconnection along the anterior limit between points $\mathrm{A}$ and $\mathrm{B}$ and the posterior limit between points $\mathrm{C}$ and $\mathrm{D}$ to the midline. The fourth step involved the intraventricular callosotomy between the median lower part of the anterior vertical disconnection line and the median lower part of the posterior vertical disconnection line. At the end of surgery, the cortical lines and the callosotomy were obstructed with oxidized cellulose and fibrinogen glue so as to avoid subdural collections.

\section{Results \\ Clinical Findings}

Six consecutive patients (4 adolescents and 2 adults) were treated using TSIPH in our department between March 2013 and April 2016 for refractory epilepsy associated with stroke. Patient characteristics are detailed in Table 1.

No etiological factor or risk factor was found in any patient after extensive workup. Ischemic events occurred in the perinatal period in 3 patients and during infancy or childhood in 3 (at ages 5, 7, and 14 years). Ischemic territories involved the anterior portion of the circle of Willis. Stroke occurred on the left side in 4 patients and on the right side in 2 patients. The vascular territory involved the middle cerebral artery (MCA) in each case. The ipsilateral motor cortices were found to be relatively spared by the ischemic lesions on MRI in all cases; ischemic lesions 


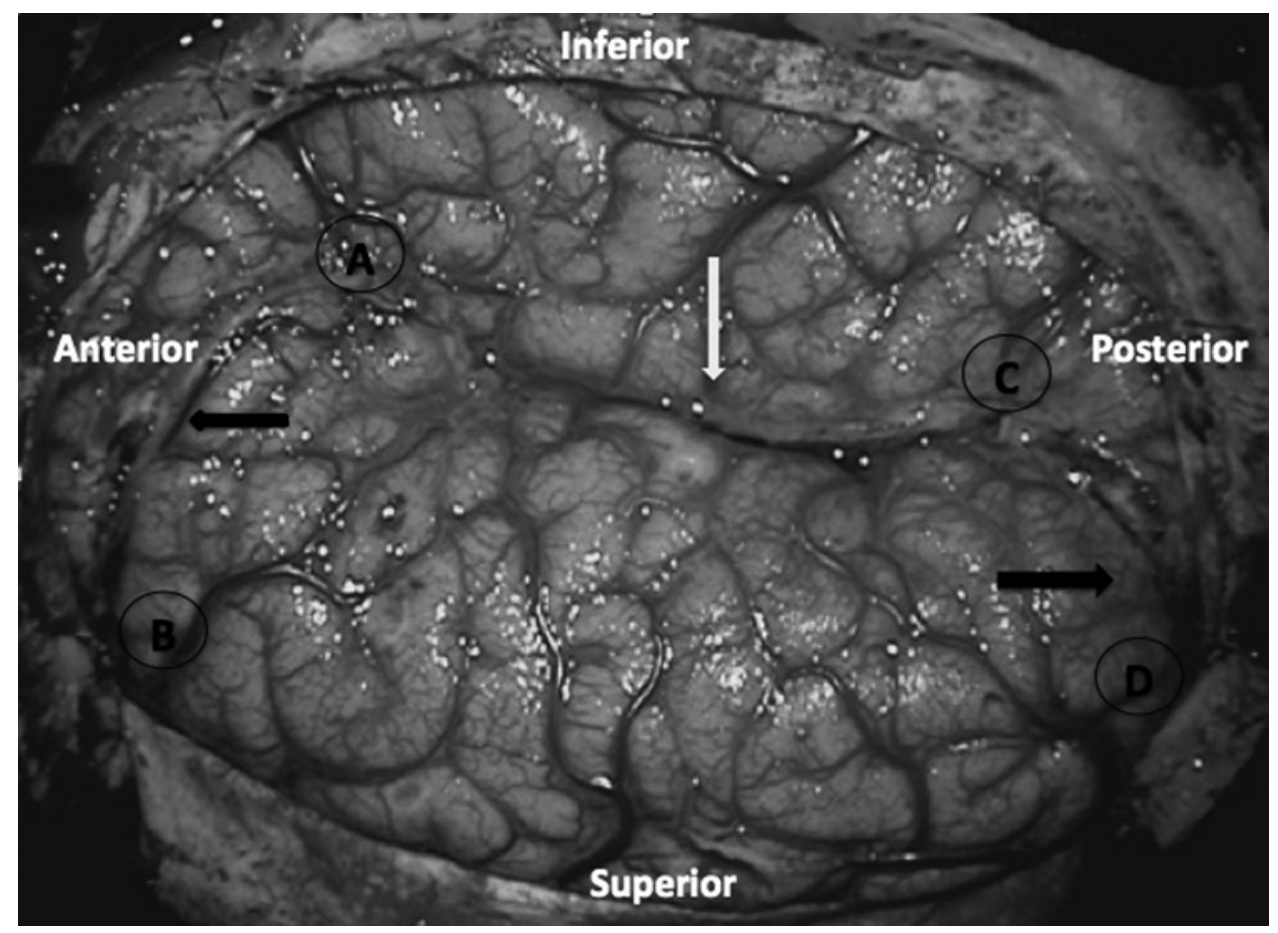

FIG. 2. Cortical exposure of the right hemisphere. The black arrows indicate the anterior and posterior disconnection lines. The white arrow indicates the sylvian fissure. The letters indicate the anterior and posterior limits of the disconnection lines.

were prominent on subcortical regions and perisylvian cortices (Fig. 4).

Seizure onset occurred at a mean age of 6 years (range 7 months-14 years). The mean interval between stroke and seizure was 3 years (range 30 days -7 years). Focal motor semiology associated with falls and possible secondary generalizations were the main seizure features (Table 1). Seizures became refractory at a median delay of 25 months (range 2-102 months). Seizures were refractory to a median of 4 antiepileptic drugs (range 3-5). One patient underwent vagus nerve stimulation without a decrease in seizure frequency or falls. The mean duration of epilepsy was 15 years (range 4-37 years). Head trauma due to seizure-related falls was frequent in the history in all patients, with 1 adult patient routinely using a cranial helmet.

The preoperative $\mathrm{mRS}$ scores were better in adolescents than in adults (score 1 or 2 vs score 3 ). No patient was found to have a visual field defect during ophthalmological assessment. Neuropsychological data are indicated in Table 1. MRI showed hemispheric ischemic involvement with signs of necrosis, porencephalic cyst, and atrophy, and the ipsilateral ventricle was large in all patients.

\section{SEEG Recordings}

The main characteristics of SEEG findings are listed in Table 1. The mean number of implanted electrodes was 12; 3 patients had bilateral implantations. There was no complication associated with SEEG. Interictal activity and seizures were recorded in each case. Generally, the distribution of interictal spikes was larger than the seizure onset zone. The EZ was characterized by the occurrence of rapid discharges affecting at least 2 cortical regions at seizure onset.

Ictal discharges were prominent in the motor system, affecting the premotor cortex (mesial and/or lateral), the primary motor cortex, and, to a variable extent, the parietal cortex (superior parietal lobule), when it was explored. One patient (case 6) had prominent anterior prefrontal involvement.

Figure 1 shows an example of ictal activity that extensively involved the explored regions of the affected hemisphere. A contralateral discharge was observed but was less tonic. Given the distribution of the EZ within the suprasylvian cortices and the presence of frank hemiplegia in all cases, suprainsular disconnection was proposed in order to spare the occipitotemporal cortex and thus avoid complete hemispherotomy.

A Wada test using propofol ${ }^{9}$ was performed in patients with left hemisphere involvement to verify the absence of a language deficit when the left internal carotid artery was injected.

\section{Perioperative Details}

The anterior and posterior limits of the resection were delineated according to the results of SEEG, particularly the anteroposterior extension of the disconnection (Fig. 5). There was no complication after surgery except for transitory hyperthermia without infection, probably due to some blood filling the subarachnoid and ventricular spaces. There was no need for transfusion during or after surgery, except for an adult patient who needed transfusion on day 6 after surgery. No patient had hydrocephalus in the postoperative period. Children spent 1 day in the 

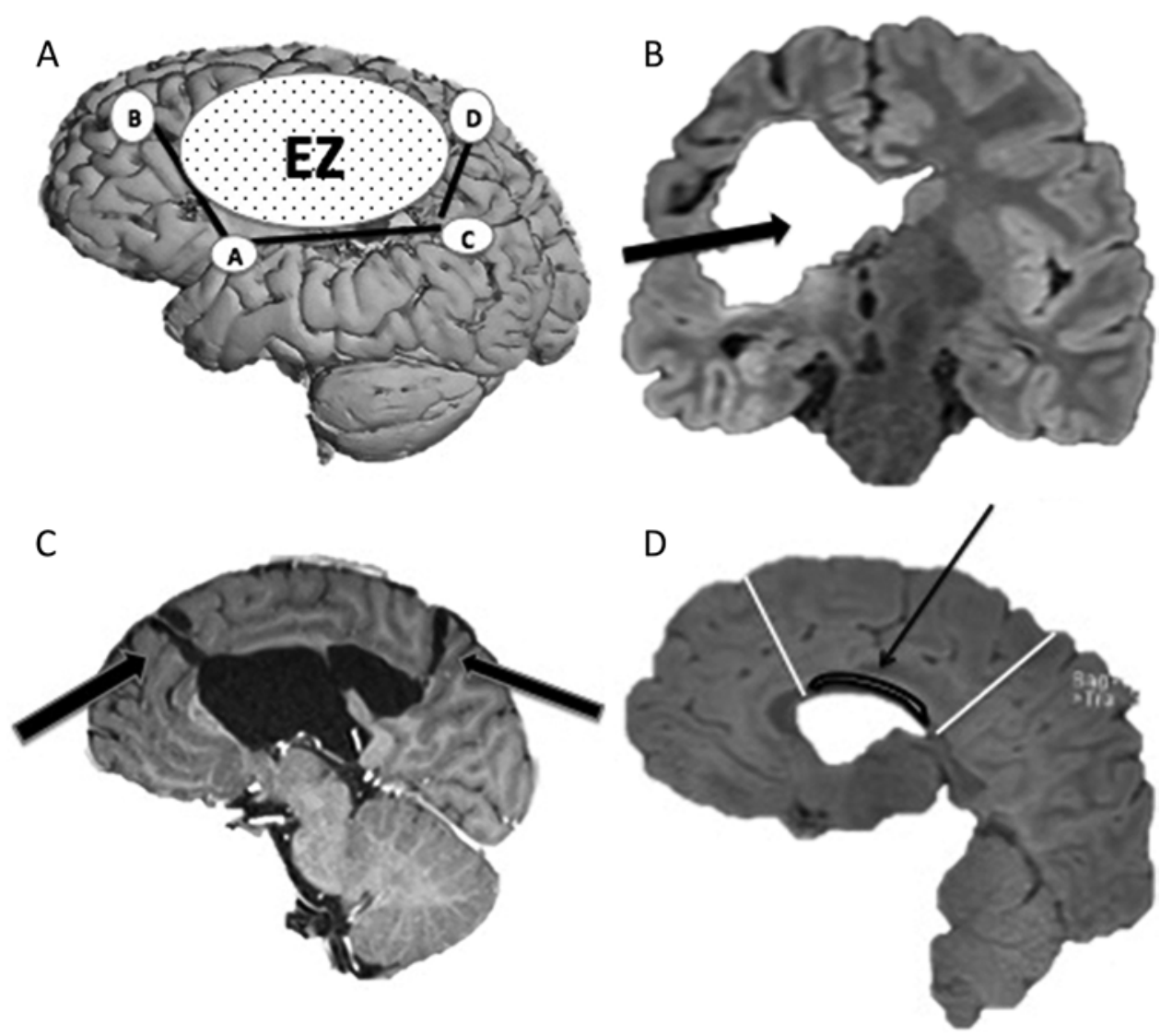

FIG. 3. Schematic of the operative procedure. A: First step. Under neuronavigation guidance, disconnection after localization of points A, B, C, and D is planned. The EZ is delineated by SEEG. B: Second step. Inferior disconnection (black arrow), coronal view. The suprainsular window to the lateral ventricle is along the inferior line (between points $A$ and $C$ ). The trajectory must be ascending if the ventricle is not enlarged. C: Third step. Anterior and posterior disconnection. Transcortical coronal disconnection until the midline. Black arrows indicate the disconnection lines. D: Fourth step. Tailored callosotomy (black arrow). The inferior margin of the corpus callosum is visualized and disconnected from inside the ventricle between the inferior aspect of the anterior and posterior disconnection lines (white lines). The area of disconnection is drawn in black.

intensive care unit, and adult patients spent 3 days. The mean hospital stay was 8 days (range $7-10$ days).

\section{Outcome}

At a mean follow-up of 28 months (range 13-46 months), there were no deaths, and no patient had hydrocephalus. In the immediate postoperative period, preexisting hemiplegia was worse, and the mRS score increased to 5 in all cases. All patients were referred to a rehabilitation center for a mean of 6 weeks (range 4-8 weeks), during which rapid improvement was observed for all patients. In terms of postoperative motor deficits, the adolescents recovered faster than adults, and recovery did not exceed 10 days. After rehabilitation, the mRS score improved in each case at least 1 point above the preoperative disability status, except for the patient in case 1, whose mRS score remained the same (score 1). The adults had more disability postoperatively than younger patients. No language deficit was noted, even in patients who underwent a leftsided procedure. Similarly, no visual deficit was observed.

The 6 patients are seizure free (Engel class I) at last follow-up (Table 1), and all are on a regimen of antiepi- leptic drug treatment. One adult patient had improved autonomy in activities of daily living due to the absence of seizures and falls. Parents noted an improvement in mood and dynamism. Children returned to regular school and began sports activities 4 months after surgery. Parents and teachers of the pediatric patients reported positive changes in behavior, with more participation and sociability. The patient in case 6 had presented with behavioral problems, such as aggressiveness and inability to attend normal school before undergoing surgery. After disconnection in this patient, marked improvement in behavior was observed, leading to better sociability and absence of aggressive behavior. Results of pre- and postoperative neuropsychological testing were available for 2 of 6 patients and remained stable with regard to the preoperative period (Table 1).

\section{Discussion}

The gold-standard treatment for drug-resistant epilepsy associated with perinatal or childhood stroke is classically based on complete hemispheric disconnection via ap- 
TABLE 1. Main clinical characteristics of the 6 patients who underwent TSIPH

\begin{tabular}{|c|c|c|c|c|c|c|}
\hline & \multicolumn{6}{|c|}{ Case No. } \\
\hline & 1 & 2 & 3 & 4 & 5 & 6 \\
\hline Sex & $M$ & $\mathrm{~F}$ & M & $M$ & $\mathrm{~F}$ & $\mathrm{~F}$ \\
\hline Age at stroke & $5 \mathrm{yrs}$ & $7 \mathrm{yrs}$ & $14 \mathrm{yrs}$ & PN & PN & PN \\
\hline Age at epilepsy onset & $6 \mathrm{yrs}$ & $7 \mathrm{yrs}$ & $14 \mathrm{yrs}$ & $\begin{array}{l}7 \text { mos (infantile } \\
\text { spasms) }\end{array}$ & $1.2 \mathrm{yrs}$ & $8 \mathrm{yrs}$ \\
\hline CVA territory & Lt MCA & Rt MCA & Lt MCA & Lt MCA & Lt MCA & Rt MCA \\
\hline Handedness & Rt & Rt & Lt & Lt & $\mathrm{Lt}$ & Rt \\
\hline Seizure semiology & Tonic motor & Partial complex & Motor & Motor & Motor + absence & Partial complex \\
\hline Falls & Yes & Yes & Yes & Yes & Yes & Yes \\
\hline Treatment & $\begin{array}{l}\text { Polytherapy } \\
\text { AED }\end{array}$ & $\begin{array}{l}\text { Polytherapy } \\
\text { AED }\end{array}$ & Polytherapy AED & $\begin{array}{l}\text { Polytherapy } \\
\text { AED + VNS }\end{array}$ & Polytherapy AED & Polytherapy AED \\
\hline \multicolumn{7}{|l|}{ SEEG } \\
\hline Age, yrs & 12 & 13 & 33 & 39 & 15 & 17 \\
\hline No. of electrodes & 11 & 12 & 8 & 11 & 8 & 13 \\
\hline SOZ regions & PM, M1 & PM, M1 & PM, M1 & PM, M1, P & PM, M1 & PF, PM, M1 \\
\hline Age at op, yrs & 12 & 14 & 37 & 41 & 16 & 17 \\
\hline Duration of hospitalization, days & 8 & 8 & 10 & 8 & 8 & 10 \\
\hline Early postop complications & $\begin{array}{l}\text { Motor degra- } \\
\text { dation }\end{array}$ & $\begin{array}{l}\text { Motor degrada- } \\
\text { tion }\end{array}$ & $\begin{array}{c}\text { Motor degradation \& } \\
\text { blood transfusion }\end{array}$ & $\begin{array}{l}\text { Motor degrada- } \\
\quad \text { tion }\end{array}$ & $\begin{array}{l}\text { Motor degrada- } \\
\quad \text { tion }\end{array}$ & $\begin{array}{l}\text { Motor degrada- } \\
\quad \text { tion }\end{array}$ \\
\hline Preop mRS score & 1 & 2 & 3 & 2 & 2 & 2 \\
\hline Postop mRS score & 1 & 1 & 2 & 1 & 1 & 1 \\
\hline Engel class & I & I & I & I & I & I \\
\hline Length of follow-up, mos & 46 & 39 & 27 & 20 & 13 & 22 \\
\hline Preop VIQ/NVIQ & $103 / 63$ & $88 / 67$ & ND & ND & $76 / 58$ & $76 / 58$ \\
\hline Postop VIQ/NVIQ & $99 / 63$ & $88 / 67$ & ND & ND & ND & ND \\
\hline Postop social \& behavioral status & Improved & Improved & Improved & Not changed & Improved & Greatly improved \\
\hline
\end{tabular}

$\mathrm{AED}=$ antiepileptic drugs; $\mathrm{CVA}=$ cerebrovascular accident; $\mathrm{M} 1=$ primary motor cortex; $N D=$ not determined; $N V I Q=$ nonverbal IQ; $P A=$ parietal cortex; $P F=$ prefrontal cortex; $\mathrm{PM}=$ premotor cortex; $\mathrm{PN}=$ perinatal; $\mathrm{SOZ}$ = seizure onset zone; $\mathrm{VIQ}=$ verbal IQ; VNS = vagus nerve stimulation.

proaches such as periinsular functional hemispherotomy, vertical parasagittal hemispherotomy, and modified periinsular hemispherotomy. ${ }^{33}$ All of these different techniques involve resection of medial temporal structures, interruption of the fibers forming the corona radiata and internal capsule, transventricular callosotomy, and disruption of the frontal horizontal fibers..$^{31,34}$ These procedures can lead to seizure freedom in $90 \%-95 \%$ of patients. ${ }^{23,34}$ However, this type of surgical management does not improve cognitive prognosis ${ }^{34}$ and carries a high risk of hemianopia, verbal memory impairment, and olfactory deficits..$^{12,34}$

There are arguments in favor of choosing disconnection surgery instead of resective options, notably to avoid the intracranial dead space created by hemispherectomy, which is associated with a risk of superficial hemosiderosis and consequently the risk of de novo epilepsy and hydrocephalus. In addition, disconnection surgery avoids the risks, such as increased incidence of subdural hematomas and draining surgeries, associated with other procedures that require wide opening of the ventricular systems to achieve access to relevant structures. Disconnection surgery is also less time consuming than resection.

In order to limit the consequences of these procedures, we propose a different strategy, the TSIPH, a partial dis- connection procedure individually tailored to the SEEG results obtained in each patient. These 6 cases, of which 2 were cases in adults, demonstrate the efficacy and absence of morbidity associated with partial tailored suprasylvian disconnection. Complete seizure control after TSIPH was achieved (100\% improvement, 5 of 6 patients completely seizure free) with a mean follow-up of 27.8 months. Currently, we have performed TSIPH in all the investigated children. Since 2012 no child with a large stroke has benefitted from a total hemispherotomy. SEEG indicated that the anterior quadrant disconnection technique ${ }^{8}$ was not indicated in such cases because the posterior limit of the epileptogenic onset zone was in the parietal area and thus posterior to the supposed central sulcus (Figs. 1 and 4).

Use of SEEG for presurgical evaluation of epilepsy associated with childhood stroke has not been specifically reported in the literature and is probably underused for this indication, where a majority of teams perform large disconnections such as hemispherotomies without necessarily performing prior intracerebral recording. ${ }^{16}$ In our series, surgery was based on the results of SEEG, which guided decisions regarding the anterior and posterior limits of the subsequent disconnection and verified the absence of involvement of other regions. SEEG is a valuable, 

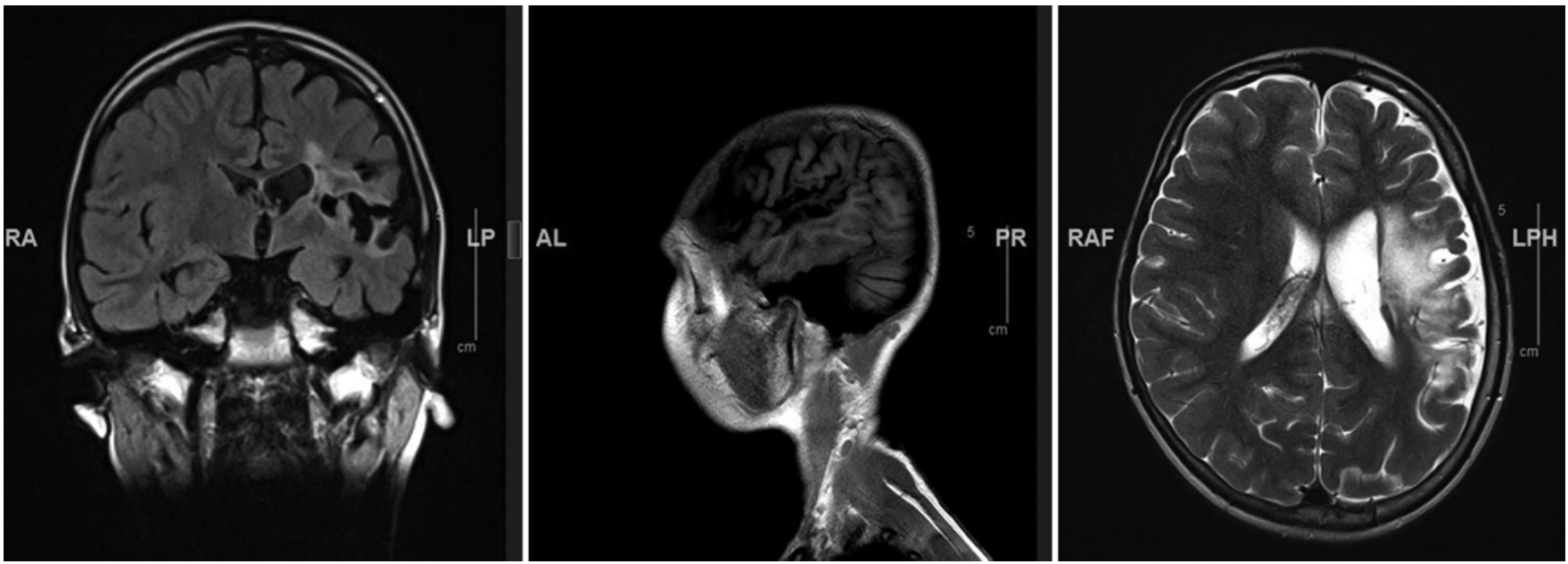

FIG. 4. Case 1. Coronal, sagittal, and axial brain MR images showing anterior and posterior extension of stroke. Note that the posterior extension exceeds the central sulcus.

invasive tool for the assessment and anatomical definition of the EZ in adults and children. ${ }^{17,18,36}$ In our series, SEEG demonstrated a main role for the premotor and precentral cortices, variably extending to the prefrontal cortex and the parietal cortex. This information, along with other clinical and imaging data, allowed disconnection of the EZ to be performed according to the specific pattern in each case, sparing temporal, occipital, and some frontal functional areas. There was no direct link between the MRI limits of the lesion and the EZ. Therefore, disconnections were guided by the SEEG results and not directly guided by the topography of the lesion on MRI.

The inferior disconnection performed during TSIPH allows disconnection of the ascending-descending path- ways, similar to classic hemispherotomy. Anterior and posterior disconnections disconnect superior intrahemispheric association pathways, such as the superior longitudinal fasciculus, inferior frontooccipital fasciculus, and, if necessary, uncinate fasciculus. Optic and memory pathways are preserved during TSIPH, thus respecting function. In this series, outcome was excellent for all patients in terms of both seizure freedom and absence of associated deficit. Tailoring disconnections in this way based on SEEG data allows a truly functional surgical approach, targeting the EZ and avoiding resection or disconnection of nonepileptogenic and functional areas. This is a reason why in our department no child with a large stroke since 2012 has benefitted from a total hemispherotomy.

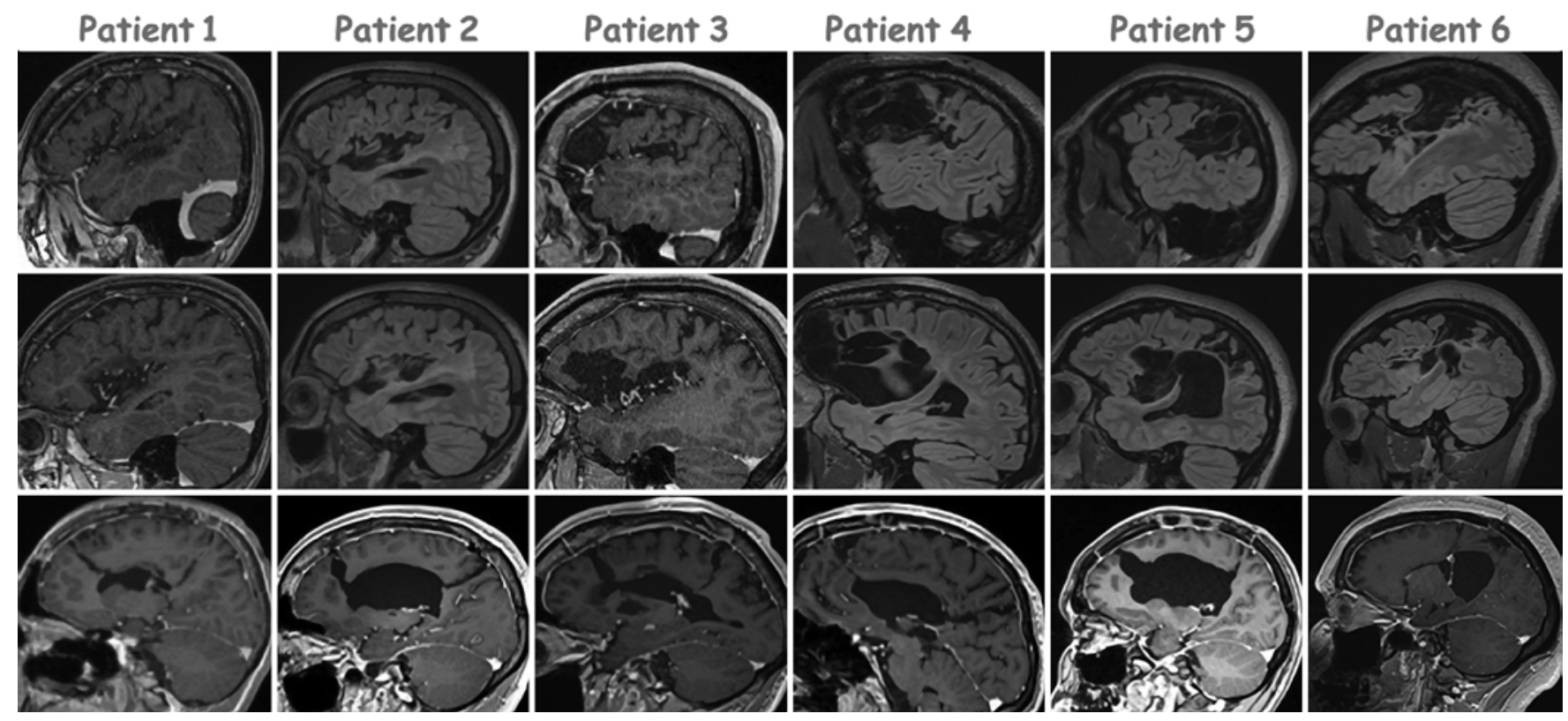

FIG. 5. Upper and Center: Sagittal MR images showing MCA stroke extension. Lower: Sagittal MR images showing the variability of the anterior and posterior limits of the TSIPH. Note the anterior complete disconnection in case 6. 


\section{Conclusions}

Since their introduction, the main goal of disconnection procedures has been optimal seizure control with minimal impact and side effects. ${ }^{16,32}$ It appears that ideally, these objectives must incorporate avoidance of nonlesional cortical areas to preserve function and cognition. From this perspective, the use of SEEG in our patients allowed us to delineate a surgical approach, sparing some territories that would otherwise have been disconnected with a classic hemispherotomy. TSIPH appears to be a safe and efficient surgical procedure for stroke-induced refractory epilepsy in children and adults and an alternative to the classic hemispherotomy.

\section{Acknowledgments}

We thank Prof. J. Régis and Prof. J. C. Sol for SEEG implantation in the 2 adult patients.

\section{References}

1. Audic F: [Aetiology, symptoms and complications of a paediatric stroke.] Soins Pediatr Pueric 38:17-19, 2017 (Fr)

2. Bartolomei F, Chauvel P, Wendling F: Epileptogenicity of brain structures in human temporal lobe epilepsy: a quantified study from intracerebral EEG. Brain 131:1818-1830, 2008

3. Bigi S, Fischer U, Wehrli E, Mattle HP, Boltshauser E, Bürki $\mathrm{S}$, et al: Acute ischemic stroke in children versus young adults. Ann Neurol 70:245-254, 2011

4. Billinghurst LL, Beslow LA, Abend NS, Uohara M, Jastrzab L, Licht DJ, et al: Incidence and predictors of epilepsy after pediatric arterial ischemic stroke. Neurology 88:630-637, 2017

5. Breitweg I, Stülpnagel CV, Pieper T, Lidzba K, Holthausen H, Staudt M, et al: Early seizures predict the development of epilepsy in children and adolescents with stroke. Eur J Paediatr Neurol 21:465-467, 2017

6. Chadehumbe MA, Khatri P, Khoury JC, Alwell K, Szaflarski JP, Broderick JP, et al: Seizures are common in the acute setting of childhood stroke: a population-based study. J Child Neurol 24:9-12, 2009

7. Cook SW, Nguyen ST, Hu B, Yudovin S, Shields WD, Vinters $\mathrm{HV}$, et al: Cerebral hemispherectomy in pediatric patients with epilepsy: comparison of three techniques by pathological substrate in 115 patients. J Neurosurg 100 (2 Suppl Pediatrics): $125-141,2004$

8. Cossu G, Lebon S, Seeck M, Pralong E, Messerer M, RouletPerez E, et al: Periinsular anterior quadrantotomy: technical note. J Neurosurg Pediatr 21:124-132, 2018

9. Curot J, Denuelle M, Busigny T, Barragan-Jason G, Kany M, Tall P, et al: Bilateral Wada test: amobarbital or propofol? Seizure 23:122-128, 2014

10. de la Vaissière S, Milh M, Scavarda D, Carron R, Lépine A, Trébuchon A, et al: Cortical involvement in focal epilepsies with epileptic spasms. Epilepsy Res 108:1572-1580, 2014

11. Dorfer C, Czech T, Mühlebner-Fahrngruber A, Mert A, Gröppel G, Novak K, et al: Disconnective surgery in posterior quadrantic epilepsy: experience in a consecutive series of 10 patients. Neurosurg Focus 34(6):E10, 2013

12. Dulay MF, Busch RM: Prediction of neuropsychological outcome after resection of temporal and extratemporal seizure foci. Neurosurg Focus 32(3):E4, 2012

13. Engel J Jr: Update on surgical treatment of the epilepsies. Summary of the Second International Palm Desert Conference on the Surgical Treatment of the Epilepsies (1992). Neurology 43:1612-1617, 1993
14. Fox CK, Mackay MT, Dowling MM, Pergami P, Titomanlio L, Deveber G: Prolonged or recurrent acute seizures after pediatric arterial ischemic stroke are associated with increasing epilepsy risk. Dev Med Child Neurol 59:38-44, 2017

15. Ganesan V, Hogan A, Shack N, Gordon A, Isaacs E, Kirkham FJ: Outcome after ischaemic stroke in childhood. Dev Med Child Neurol 42:455-461, 2000

16. Ghatan S, McGoldrick P, Palmese C, La Vega-Talbott M, Kang H, Kokoszka MA, et al: Surgical management of medically refractory epilepsy due to early childhood stroke. J Neurosurg Pediatr 14:58-67, 2014

17. Gonzalez-Martinez J, Lachhwani D: Stereoelectroencephalography in children with cortical dysplasia: technique and results. Childs Nerv Syst 30:1853-1857, 2014

18. Gonzalez-Martinez J, Najm IM: Indications and selection criteria for invasive monitoring in children with cortical dysplasia. Childs Nerv Syst 30:1823-1829, 2014

19. Harteman JC, Groenendaal F, Kwee A, Welsing PM, Benders MJ, de Vries LS: Risk factors for perinatal arterial ischaemic stroke in full-term infants: a case-control study. Arch Dis Child Fetal Neonatal Ed 97:F411-F416, 2012

20. Holt RL, Mikati MA: Care for child development: basic science rationale and effects of interventions. Pediatr Neurol 44:239-253, 2011

21. Isnard J, Taussig D, Bartolomei F, Bourdillon P, Catenoix H, Chassoux F, et al: French guidelines on stereoelectroencephalography (SEEG). Neurophysiol Clin 48:5-13, 2018

22. Koch CA: How should patients with porencephaly and generalized seizures such as West syndrome be treated? Brain Dev 21:566, 1999

23. Kovanda TJ, Rey-Dios R, Travnicek J, Cohen-Gadol AA: Modified periinsular hemispherotomy: operative anatomy and technical nuances. J Neurosurg Pediatr 13:332-338, 2014

24. Lvova OA, Shalkevich LV, Dron AN, Lukashchuk MY, Orlova EA, Gusev VV, et al: [Predictors of epilepsy in children after ischemic stroke.] Zh Nevrol Psikhiatr Im S S Korsakova 116:4-8, 2016 (Russian)

25. Mallick AA, Ganesan V, Kirkham FJ, Fallon P, Hedderly T, McShane T, et al: Childhood arterial ischaemic stroke incidence, presenting features, and risk factors: a prospective population-based study. Lancet Neurol 13:35-43, 2014

26. Mallick AA, O'Callaghan FJ: The epidemiology of childhood stroke. Eur J Paediatr Neurol 14:197-205, 2010

27. Mallick AA, O'Callaghan FJ: Risk factors and treatment outcomes of childhood stroke. Expert Rev Neurother 10:1331-1346, 2010

28. McCrea N, Saunders D, Bagkeris E, Chitre M, Ganesan V: Diagnosis of vertebral artery dissection in childhood posterior circulation arterial ischaemic stroke. Dev Med Child Neurol 58:63-69, 2016

29. Ment LR, Duncan CC, Ehrenkranz RA, Lange RC, Taylor $\mathrm{KJ}$, Kleinman CS, et al: Intraventricular hemorrhage in the preterm neonate: timing and cerebral blood flow changes. J Pediatr 104:419-425, 1984

30. Mohamed AR, Freeman JL, Maixner W, Bailey CA, Wrennall JA, Harvey AS: Temporoparietooccipital disconnection in children with intractable epilepsy. J Neurosurg Pediatr 7:660-670, 2011

31. Morino M, Shimizu H, Ohata K, Tanaka K, Hara M: Anatomical analysis of different hemispherotomy procedures based on dissection of cadaveric brains. J Neurosurg 97:423-431, 2002

32. Rasmussen T: Hemispherectomy for seizures revisited. Can J Neurol Sci 10:71-78, 1983

33. Scavarda D, Imada V, Rolland AC, Lortie A, Mercier C, Carmant L: Peri-insular hemispherotomy in children: a single institution experience. Minerva Pediatr 62:1-7, 2010

34. Scavarda D, Major P, Lortie A, Mercier C, Carmant L: Pe- 
riinsular hemispherotomy in children with stroke-induced refractory epilepsy. J Neurosurg Pediatr 3:115-120, 2009

35. Singh RK, Zecavati N, Singh J, Kaulas H, Nelson KB, Dean NP, et al: Seizures in acute childhood stroke. J Pediatr 160:291-296, 2012

36. Taussig D, Lebas A, Chipaux M, Jan M, Fohlen M, Bulteau C, et al: Stereo-electroencephalography (SEEG) in children surgically cured of their epilepsy. Neurophysiol Clin 46:315, 2016

37. Tuppin P, Samson S, Woimant F, Chabrier S: Management and 2-year follow-up of children aged 29 days to 17 years hospitalized for a first stroke in France (2009-2010). Arch Pediatr 21:1305-1315, 2014

38. Yang JS, Park YD, Hartlage PL: Seizures associated with stroke in childhood. Pediatr Neurol 12:136-138, 1995

\section{Disclosures}

The authors report no conflict of interest concerning the materials or methods used in this study or the findings specified in this paper.

\section{Author Contributions}

Conception and design: Scavarda. Acquisition of data: Scavarda, Villeneuve, Girard, Bartolomei. Analysis and interpretation of data: Scavarda, Trébuchon, Lépine, Villeneuve, McGonigal, Milh, Bartolomei. Drafting the article: Scavarda, Trébuchon, Bartolomei. Critically revising the article: Cavalcante, Milh, Bartolomei. Reviewed submitted version of manuscript: Scavarda. Approved the final version of the manuscript on behalf of all authors: Scavarda. Administrative/technical/material support: Scavarda, Girard.

\section{Correspondence}

Didier Scavarda: Hôpital de la Timone, Marseille, France. didier. scavarda@ap-hm.fr. 